\title{
Foreign national mentally disordered offenders' care pathways through UK secure services
}

\author{
Sarah-Jane Spencer, ${ }^{1}$ Paul Gilluley, ${ }^{2}$ Bradley Hillier ${ }^{3,4}$
}

The Psychiatrist (2013), 37, 331-335, doi: 10.1192/pb.bp.112.039735

${ }^{1}$ Metropolitan Remand Reception Centre, Silverwater, Australia; ${ }^{2}$ John Howard Centre, London, UK; ${ }^{3}$ Institute of Psychiatry, London, UK; ${ }^{4}$ Broadmoor High Secure Hospital, Crowthorne, UK Correspondence to Sarah-Jane Spencer (sarah.spencer@justicehealth. nsw.gov.au)

First received 18 Apr 2012, final revision 30 Jan 2013, accepted 26 Mar 2013
Summary Over recent years UK immigration legislation and procedures have changed significantly. Although these developments affect many foreign national mentally disordered offenders, the professionals caring for them are often unaware of the implications of these changes and the possible alternative care pathways. In this article we explore the amendments and the options available for this patient group, and highlight the ethical difficulties that professionals can face.

Declaration of interest None.
Throughout this article the term 'foreign national' is used to describe an individual who is not a British citizen, but holds citizenship of a sovereign state recognised by the UK, and has not been granted asylum. This therefore includes any individual who may (or may not) have a legal right to remain in the UK and who falls outside the category of citizenship.

In April 2006, Home Secretary Charles Clarke made a statement to the House of Commons regarding the review of deportation of foreign national prisoners. ${ }^{1}$ This included an admission that over 1000 foreign national prisoners had been released following completion of their sentence without the consideration of deportation. Throughout the summer of 2006 the media continued to publish stories regarding failure of the Home Office to appropriately manage foreign national prisoners. ${ }^{2}$ In a written update issued by the subsequent Home Secretary, John Reid, it was announced that there were over 700 foreign national prisoners facing deportation. ${ }^{3}$ Liam Byrne, then minister for immigration, created the UK Border Agency and the drive to deport foreign national prisoners convicted of serious offences continued. Between 2007 and 2010 a total of 20360 foreign national prisoners were deported from the UK. In 2010, 5325 were deported. ${ }^{4}$ Under the UK Borders Act 2007, foreign national prisoners sentenced to $\geqslant 12$ months' imprisonment became subject to automatic deportation with an out-of-country right of appeal only.

A dedicated case-working team was set up within the UK Border Agency Casework Directorate to collect information on and work with foreign national mentally disordered offenders. The Directorate subsequently produced policy with the Ministry of Justice regarding the repatriation and deportation of these foreign nationals. ${ }^{5}$ They are exempt from automatic deportation under the UK Borders Act 2007 and are considered under the old guidelines, according to the Immigration Act 1971, namely they can only be deported when it is deemed to be in the public interest.

The interaction between immigration legislation and the processes leading to the deportation of foreign national offenders without mental disorder is complex in itself and subject to ongoing legal challenge, but regarding foreign national offenders who have a mental disorder there is an entirely new level of complexity. When attempting to develop a care pathway for this group of individuals within secure mental health services additional consideration needs to be given to:

- the Mental Health Act status

- response to treatment for mental disorder

- the role of the Ministry of Justice, and

- the role of the UK Border Agency.

Within our own clinical practice we encountered a number of cases where these issues became prominent, leading us to review the issue across the service.

\section{Situation in West London Mental Health NHS Trust}

In 2008 data were gathered to establish the number of foreign national mentally disordered offenders who had been admitted to West London Mental Health NHS Trust's secure services in the previous 5 years. The experiences and knowledge of professionals relating to patients' immigration status were also surveyed. Of all admissions during this period, approximately a quarter were foreign national mentally disordered offenders $(n=74)$ and the immigration status was unknown in a quarter of these individuals $(n=19)$.

Despite the fact that a significant number of admissions were foreign national mentally disordered offenders, the professionals reported variable or limited knowledge of the 
implications of their immigration status on their care pathway.

\section{Is deportation likely?}

The guidance in Fig. 1, although not specifically written to relate to mentally disordered offenders, gives some indication to the decision-making process within the UK Border Agency/Ministry of Justice relating to deportation decisions about offenders in general. It may be of use for treating teams as an indication as to whether there is a likelihood that immigration considerations may be of relevance for their own foreign national patients.

In secure settings, a significant proportion of patients will have a concurrent restriction order made under Section 41 of the Mental Health Act 1983 (as amended 2007) as it was deemed 'necessary for the protection of the public from serious harm'. It is these individuals who are likely to be considered for deportation when they no longer require hospital care.

If it is unlikely that deportation may be pursued by the UK Border Agency, then arguably the care pathway is less complicated for the treating team: unless the individual wants to return to their home country, the rehabilitation process should continue with the aim of discharging them into the community.

If it is apparent that deportation may be a possibility, consideration should be given to all the options (Fig. 2). For restricted patients, the UK Border Agency does not begin considering deportation until a mentally disordered offender is granted a conditional discharge under Section 42 by the mental health review tribunal or the Ministry of Justice. It is at this stage that the often lengthy process of appeal against deportation may begin should the individual seek to remain in the UK. The treating team are not necessarily informed that deportation is being considered in individual cases until the patient is ready to be considered for discharge into the community. Consequently, the patient may remain in hospital at significant financial expense but in some cases also with deterioration in their mental health under these stressful proceedings.

\section{Alternative care pathways - repatriation}

In considering the care pathways that are available to foreign national mentally disordered offenders who may fall into the category of those under consideration by the UK Border Agency for deportation on Section 42 conditional discharge, the possibility of repatriation by the treating team could be considered. Repatriation, or the process of returning an individual to their country of birth, is recognised as a care pathway in the context of the Mental Health Act 1983. This can be carried out with the consent and engagement of the service user (voluntary repatriation) as well as under Mental Health Act compulsion (involuntary repatriation), should it be considered to be in the best interests of the patient.

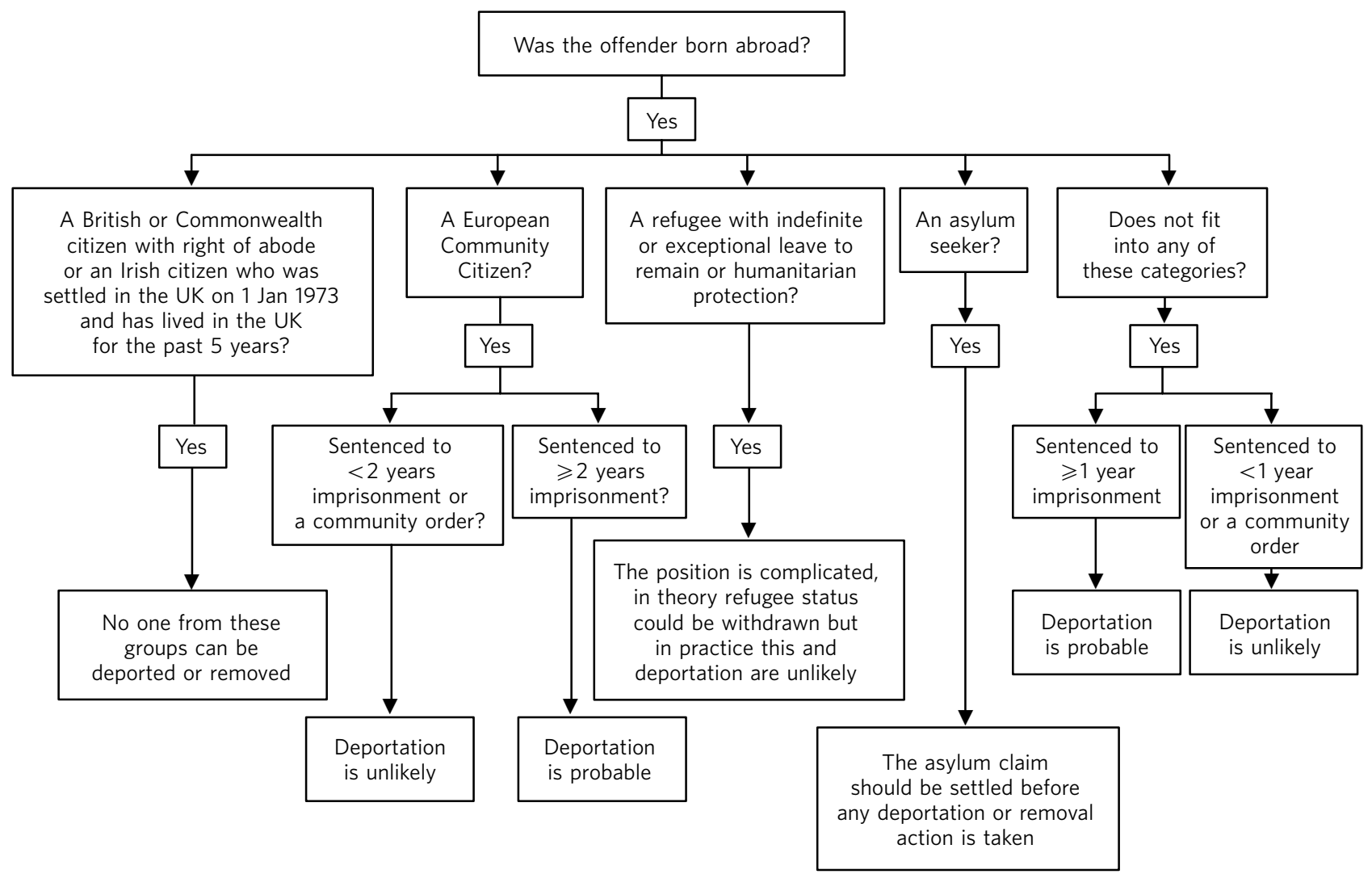

Fig 1 Decision tree to determine the likelihood of deportation for a mentally disordered offender by the UK Border Agency. Foreign national mentally disordered offenders are exempt from automatic deportation and considered under the guidelines in the Immigration Act 1971, i.e. deported when in the public interest. 


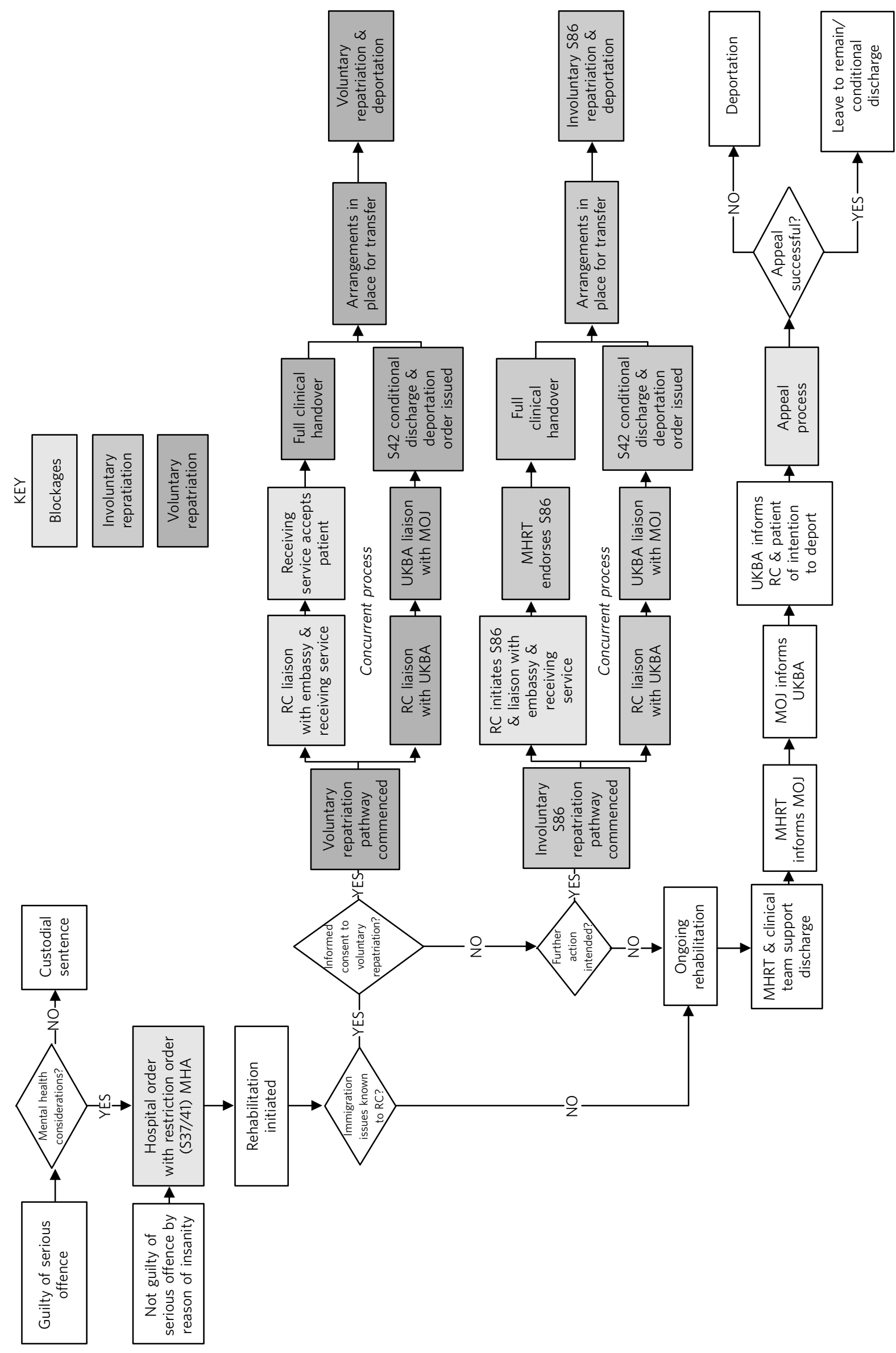

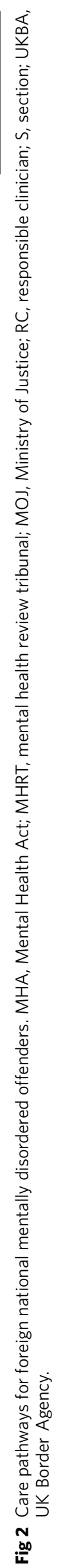


When reaching a decision about incorporating repatriation into the care pathway a frequently cited concern relates to how the quality of psychiatric care that patients receive in different countries varies greatly. It is also valid to acknowledge that although it may be the case that in their country of origin an individual may not receive treatment comparable with that in the UK, there may be other important benefits for the patient. Such examples include fewer language or cultural barriers to overcome and potentially more support from family and friends.

There are possible implications for the patient's treating team; transferring an individual to continue their treatment in their home country ensures that the legal responsibilities outlined in Section 117 of the Mental Health Act 1983 to provide after-care services are fulfilled. This is in contrast to a scenario where an individual is fully rehabilitated and granted a conditional discharge, only to then be deported to their country of origin; UK immigration authorities are under no obligation to contact mental health services abroad to arrange appropriate follow-up.

An additional consideration is that an individual need simply be 'fit to travel' to be repatriated rather than 'fit for discharge'. In a secure setting this could result in significantly shorter admissions and obvious financial savings should repatriation be a feasible option in the care pathway.

\section{Voluntary repatriation}

Voluntary repatriation entails considerable liaison by the responsible clinician or members of their team with a number of different agencies, including embassies, mental health services in other countries (frequently involving time differences and language difficulties), and airlines. For a patient to be repatriated the responsible clinician has to be satisfied that:

- the patient is willing to return

- the authorities in their home country are prepared to accept them

- there are acceptable arrangements for continued treatment, including detention if appropriate

- there are suitable transport arrangements.

Once these provisions are met, the responsible clinician can initiate the process of repatriation. For restricted patients this commences by making a request for repatriation to the Mental Health Unit at the Ministry of Justice. A conditional discharge can then be issued by the Justice Secretary under Section 42 of the Mental Health Act 1983 and the patient conveyed, in accordance with the conditions of the discharge, to their destination country as set out in the Ministry of Justice guidance relating to this procedure. ${ }^{5}$

Green \& Nayani ${ }^{6}$ describe their experiences working in a busy general adult psychiatric intensive care unit in central London, organising primarily voluntary repatriations in patients detained under Part 2 of the Mental Health Act. They highlight that the ease with which repatriation could be arranged varied significantly depending on the destination country, and was contingent on the amount of assistance (and experience) provided by the embassy involved. They recommend making contact with the embassy at the earliest opportunity both to obtain relevant background information on the individual and to avoid unnecessary delays.

\section{Formal (involuntary) repatriation under Section 86 of the Mental Health Act 1983}

If an individual's treating team believes that repatriation would be in their best interests, but the patient does not wish to return to their home country, repatriation under Section 86 can be considered. This gives the Justice Secretary the power to authorise the removal of patients who are either irrationally opposed to their removal or unable to express a view, after obtaining the approval of a mental health review tribunal. Formal repatriation can only be used when a patient is detained for in-patient treatment, and is not to be used when they are likely to be discharged within 6 months, so consideration of this option should occur in the early stages of a patient's admission.

There are significant ethical issues associated with making decisions about repatriation of foreign national mentally disordered offenders, which extend across the whole spectrum, from the quality of receiving services and stigma of mental health problems as compared with the UK, to the human rights implications of repatriation to specific countries which may be subject to circumstances of war or martial rule. Although detailed consideration of these ethical issues is beyond the scope of this article, we highlight the need for checks and measures to run in parallel with the hospital admission of an individual who may be subject to scrutiny by the immigration authorities to ensure that these are not neglected, and so a mental health team can be fully appraised of all the options available in designing a care pathway which may ultimately be in the patient's best interests.

\section{Conclusions}

A significant number of mentally disordered offenders admitted to secure services in the London area are foreign nationals and may have uncertain immigration status. There are no robust systems in place currently to ensure that the immigration proceedings are carried out or taken into consideration in parallel to their mental health treatment.

Under present practice the Mental Health Unit at the Ministry of Justice will inform the Mentally Disordered Offenders Unit at the UK Border Agency of foreign national mentally disordered offenders who are detained under a restriction order when the order is made, but the treating team are not informed that deportation is being considered in individual cases until the patient is ready to be considered for discharge into the community. While this system is in place we would suggest that mental health trusts consider enquiring as to an individual's nationality and of any known immigration issues at the point of admission, so the treating teams can consider possible interaction with the care pathway.

From an ethical perspective, trends in immigration policy across the European Union indicate that restrictions on the movement of foreign nationals are likely to continue. This sensitive issue remains one for our political masters rather than for doctors. Consequently, it would be desirable 
for there to be some guidance from professional bodies, or policy put in place by trusts. Undoubtedly, opinion will be divided on whether it is appropriate or ethical for the psychiatrist or multidisciplinary team to be proactively involved in sharing information of this nature, making decisions on quality of care and best interests in relation to services abroad, and being involved in the process of deportation itself.

\section{About the authors}

Dr Sarah-Jane Spencer MA MBBS MRCPsych LLM, Consultant Forensic Psychiatrist, Metropolitan Remand Reception Centre, Silverwater, Australia. Dr Paul Gilluley MBChB BSc (Hons) FRCPsych, Head of Forensic Services, John Howard Centre, London, UK. Dr Bradley Hillier BMBCh MA(Oxon) MRCPsych, Specialty Trainee in Forensic Psychiatry, Institute of Psychiatry Forensic Rotation, and Broadmoor High Secure Hospital, Crowthorne, UK.

\section{References}

1 House of Commons. Parliamentary Debates: Deportation and Removals. Hansard 2006; 3 May: columns 970-3.

2 Travis A. Foreign prisoners scandal deepens as Reid revises figures. The Guardian 2006; 16 May.

3 House of Commons. Written Statements: Deportation of Removal of Foreign Nationals. Hansard 2006; 23 May: columns 78-81.

4 Vine J. A Thematic Inspection of How the UK Border Agency Manages Foreign National Prisoners. Independent Chief Inspector of the UK Border Agency, 2011.

5 Ministry of Justice. Foreign National Restricted Patients: Guidance on Repatriation. Ministry of Justice, 2009.

6 Green L, Nayani T. Repatriating psychiatric patients. Psychiatr Bull 2000; 24: $405-8$. 